\title{
COMPETITION, PREDATION, AND DENSITY-DEPENDENT MORTALITY IN DEMERSAL MARINE FISHES
}

\author{
Mark A. Hixon ${ }^{1,3}$ And GeOfFrey P. JONes ${ }^{2}$ \\ ${ }^{1}$ Department of Zoology, Oregon State University, Corvallis, Oregon 97331-2914 USA \\ ${ }^{2}$ Centre for Coral Reef Biodiversity, School of Marine Biology and Aquaculture, James Cook University, Townsville, \\ Queensland 4811 Australia
}

\begin{abstract}
The relative roles of competition and predation in demographic density dependence are poorly known. A tractable experimental design to determine such effects and their interactions for demersal (seafloor oriented) fishes and similar sedentary species is cross-factoring multiple densities of new recruits with the presence and absence of predators. This design allows one to distinguish between density-dependent mortality due to competition alone, predation alone, or an interaction between the two, especially when supplemental field observations are available. To date, 14 species of marine fish have been examined with some variant of this design, and for 12 species predation was demonstrated to be the sole or major cause of density dependence. However, as competition may be slow acting relative to predation, the importance of competition can be underestimated in shortterm experiments. On the Great Barrier Reef, we conducted a long-term field experiment in which multiple densities of new recruits of a planktivorous damselfish were cross-factored with the presence or absence of resident piscivorous fish on patch reefs. During the first 10 months, no density-dependent mortality was detected, regardless of whether resident predators were present or absent. By the end of the experiment at 17 months, per capita mortality was strongly density dependent and highly compensatory in both predator treatments; all reefs ultimately supported nearly the same adult density regardless of experimental treatment. Examination of treatment effect sizes suggested that competition was the main source of density-dependent mortality, with predation being merely a proximate agent of death. We hypothesize that predators were ineffective in this system compared with similar studies elsewhere because prey density was low relative to ample prey refuges provided by highly complex corals. Combined with previous studies, these findings indicate that density-dependent mortality in demersal marine fishes is often caused by interplay of predation and competition, whose roles may be altered by variation in habitat complexity and larval supply. These conclusions are relevant to marine fisheries models, which typically assume that density dependence is due solely to intraspecific competition.
\end{abstract}

Key words: competition; coral-reef fishes; demersal marine fishes; density dependence; fisheries biology; growth; mortality; predation; prey refuges; survivorship.

\section{INTRODUCTION}

Demographic density dependence is necessary for population regulation, so identifying and preserving compensatory processes is essential for both understanding population dynamics and implementing effective conservation and management (review by Hixon et al. 2002). Although competition and predation have long been recognized as the sources of direct density dependence, the relative, combined, and synergis-

Manuscript received 17 September 2004; revised 2 May 2005; accepted 16 May 2005. Corresponding Editor: S. G. Morgan.

${ }^{3}$ E-mail: hixonm@science.oregonstate.edu tic roles of these interactions in regulating populations have received relatively little attention. This is despite the fact that the community-level ramifications of both interactions have been studied intensively, although mostly on land (reviews by Sih et al. 1985, Osenberg and Mittelbach 1996, Gurevitch et al. 2000, Chase et al. 2002).

At the population level, determining whether competition or predation or some combination is the source of density dependence can be challenging. The fact that predators eventually eat nearly all individuals in a population before the prey die of other causes does not mean that predation is necessarily a source of density 
dependence. Individuals weakened or exposed by competition, perhaps with subsequent effects of disease or parasites, are often eaten before dying of starvation or pathogens. In such cases, competition is the ultimate cause of density dependence, and predation is merely the proximate agent of death. For predation to cause density-dependent mortality of prey, there must be some combination of an aggregative response or Type 3 functional response over short time periods, or of a developmental response or appropriate numerical response over longer temporal scales (reviews by Murdoch and Oaten 1975, Taylor 1984). Directly determining the presence of such predatory responses is problematic, especially in systems with multiple species of predator (reviews by Polis et al. 1989, Sih et al. 1998, Abrams and Ginzburg 2000).

The importance of examining competition and predation simultaneously in studies of density dependence lies in the potential for interactions or synergistic effects (reviews by Sih et al. 1985, 1998, Gurevitch et al. 2000). Predation may moderate competition among prey (reviews by Connell 1975, Gurevitch et al. 2000). Alternatively, at high densities with consequent competition for food, the slower growth of young individuals may make them more susceptible to predation for a longer period (reviews by Sogard 1997, Jones and McCormick 2002). Predation may also induce competition among prey for refuge space (reviews by Jeffries and Lawton 1984, Hixon and Beets 1993). Interference competitors may displace inferior competitors from relatively safe microhabitats, rendering them more susceptible to predation. In such cases, densitydependent mortality of prey may occur only where both their competitors and predators are present (Carr et al. 2002, Holbrook and Schmitt 2002).

\section{Experimental test for the source of density-dependent mortality}

Interactive effects of predation and competition can be revealed by factorial experiments that manipulate both predators and potential competitors orthogonally (Sih et al. 1985, Gurevitch et al. 2000). Unfortunately, such field manipulations are often extremely difficult. Of 139 experiments reviewed by Sih et al. (1985), only 17 manipulated both predators and competitors. Harrison and Cappuccino (1995) reviewed experimental tests for the presence of density dependence caused by predation and competition in both invertebrates (64 tests) and vertebrates (40 tests). Over $89 \%$ of 47 studies designed to test for competition (bottom-up density dependence) found it, whereas only $38.5 \%$ of 13 studies designed to test for predation in the broadest sense (topdown density dependence) found it. Competition caused density dependence among invertebrates (mostly insects) much more frequently than predation, whereas competition and predation were more equally evident as sources of density dependence in verte- brates. Combined and synergistic effects were not examined.

Additionally, although predators can be recognized by careful observation, identifying putative heterospecific competitors to manipulate can be difficult, especially in complex biotas. These issues are further complicated when species are distributed as metapopulations (Hixon et al. 2002). Sandin and Pacala (2005a) have suggested an observational means of distinguishing competitive vs. predatory sources of population regulation in such systems based on analytical models.

If the specific goal is to examine the relative roles of competition and predation in causing within-generation, density-dependent mortality in a local population over a particular time period, an effective experimental approach is to examine the per capita mortality rates of a naturally occurring range of densities of a prey species in both the presence and absence of its predators (Caley et al. 1996, Forrester and Steele 2000, Hixon and Webster 2002). Fig. 1 (cf. Forrester and Steele 2000, Hixon and Webster 2002) shows the four alternative outcomes of this experimental design based on two reasonable assumptions, both of which are tested by examining the results of the experiment. First, we assume that prey mortality in fact increases in the presence of predators, which is true in every study we have examined. Second, we assume that there is no inverse density dependence (or depensation) in mortality, which is not always the case (e.g., marine fishes: Booth 1995, Sandin and Pacala 2005b). Given these assumptions, the four possible experimental outcomes provide insight on the presence and source of density dependence as follows:

1) The null outcome is that prey mortality is density independent regardless of the presence or absence of predation (Fig. 1A, Case 1). In this scenario, mortality is not a source of local density dependence, and predation simply adds some level of density-independent loss. This outcome has been proposed as evidence for "recruitment limitation" (sensu, Doherty and Fowler 1994, Doherty 1998; but see Doherty 2002, and see also Chesson 1998, Hixon 1998, Armsworth 2002, Sandin and Pacala 2005a). Of course, population regulation can still occur via processes other than mortality (e.g., marine fishes: Hixon and Webster 2002, Sandin and Pacala 2005a).

2) If mortality is density dependent only in the experimental absence of predators, then predation normally keeps prey densities below levels where competition occurs (Fig. 1B, Case 2). In this scenario, competition is the sole potential source of density-dependent mortality, but is not normally expressed.

3) If mortality is density dependent only in the presence of predators, then predation is certainly at least the proximate source of density dependence (Fig. 1C). The question then becomes whether competition is necessary for predation to be effective, such as where competition for physical refuges exposes excess prey to 


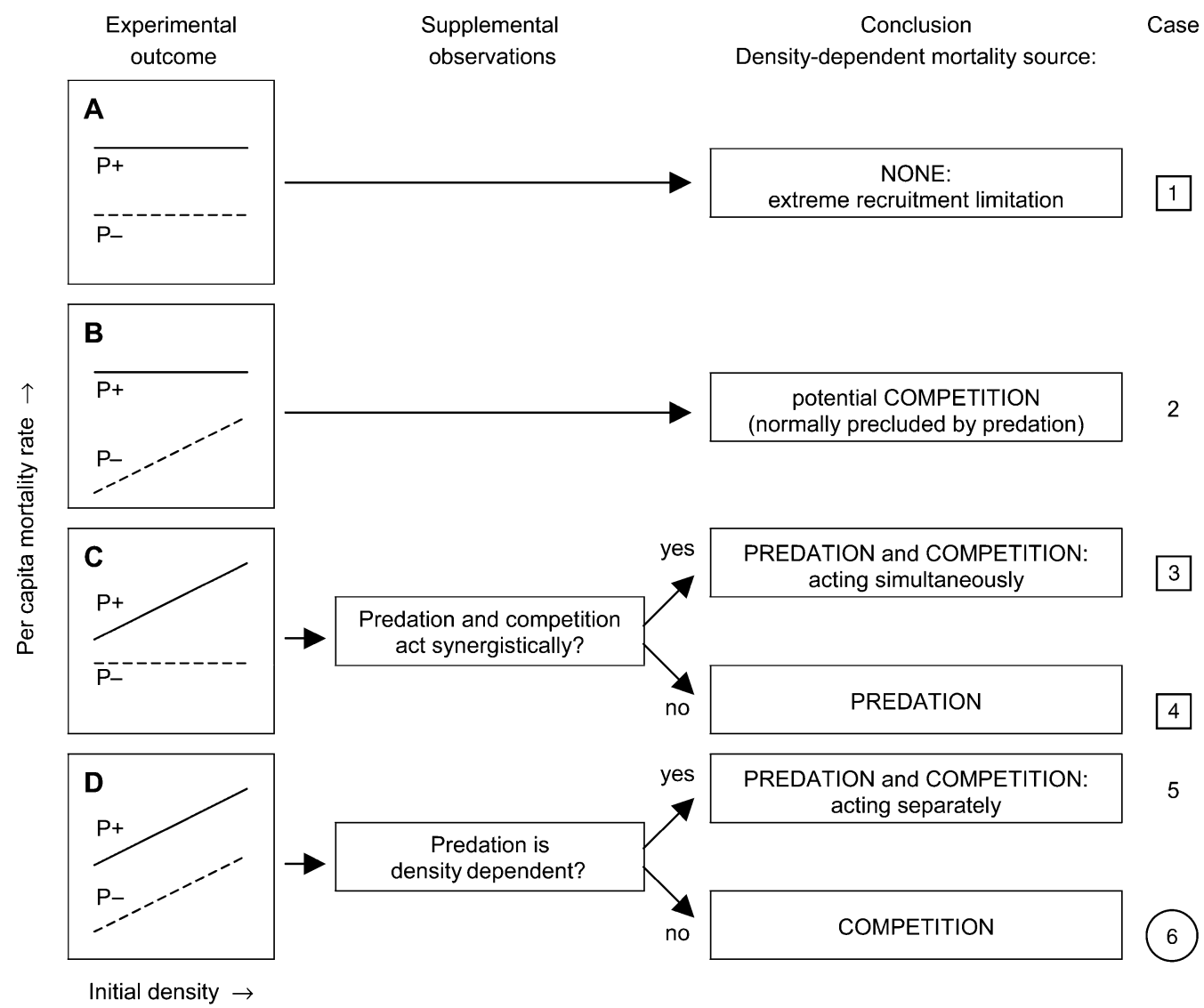

FIG. 1. Source of density-dependent mortality determined from alternate outcomes (some with required supplemental observations) of an experimental design that cross-factors a range of densities of new recruits with the presence $(\mathrm{P}+)$ and absence $(\mathrm{P}-)$ of their predators. Note that the density-dependent curves may be linear or curvilinear. For outcome D, the curves will probably not be parallel in Case 5. Cases demonstrated previously in demersal marine fishes are shown in squares (see Table 1). Case 6, demonstrated by this study, is circled.

predators (Case 3). This question can be answered by supplemental behavioral observations in the case of interference competition, and by full orthogonal manipulations of predators and potential competitors in the case of interspecific competition. If competition does not play a role, then predation is the sole source of density-dependent mortality, which is predicted to occur when predation acts rapidly compared to competition (Case 4).

4) Finally, if mortality is density dependent regardless of the presence or absence of predators (Fig. 1D), then there are two alternative causes. First, density dependence may normally be caused by predation alone, or in the absence of predators, by competition alone (Case 5). In this scenario, it would be improbable that the mortality curves would be parallel, as illustrated in Fig. 1D, but both would have positive slopes. Second, competition may be of overriding importance regardless of whether predators are present or absent, such that predation is not a source of density dependence (Case 6). In this scenario, the two mortality curves would be parallel, with predators merely adding some level of density-independent mortality onto the density dependence already caused by competition.

Three caveats are important in applying this experimental design. First, the temporal scale of the experiment (i.e., the rates at which competition and predation occur in relation to the duration of the experiment) will affect both outcome and interpretation. During the lifespan of a particular cohort, predation often acts early and rapidly by affecting small juvenile prey (review by Murdoch and Oaten 1975), especially in demersal marine fishes (reviews by Hixon 1991, Myers and Cadigan 1993). In contrast, although competition may retard individual rates of growth and development in the short term (Jones 1986, 1987), it may take much more time for competition alone to cause substantial mortality in the absence of predators, especially in the case of exploitative competition for food (vs. aggression and other forms of interference competition; Jones 1987, Jones and McCormick 2002). In the long run, if it takes the same time for density-dependent mortality to occur regardless of whether predators are present or absent, then competition can be considered the ultimate source 
of density dependence. In any case, if it takes substantial time for density-dependent mortality to occur, then short-term experiments may conclude in error that mortality is density independent.

Second, the experiments described here are designed to determine the circumstances under which densitydependent mortality occurs over specific natural ranges of density and scales of space and time, not the relative importance of density dependence vs. density independence in general. The latter question is certainly valuable in its own right, and relevant analyses have been developed (see Schmitt et al. 1999, Osenberg et al. 2002), but this issue is not the focus of this synthesis. We see substantial density-independent processes as ubiquitous and important in the marine realm, yet understanding population regulation requires identification of the processes causing density dependence.

Third, the four alternatives illustrated in Fig. 1 obviously represent ideal cases. In reality, the mortality curve can be linear or curvilinear, and vary from strongly density dependent (steep slope) to density independent (zero slope). Fortunately, fully factorial experimental designs are amenable to both regression approaches and two-factor (prey density $\times$ predator presence-absence) ANOVA. Interpretation of outcomes can be facilitated statistically by examining the relative magnitude of density vs. predation effects (Graham and Edwards 2001). For example, if the statistical effect size of density is substantial and that of predation is negligible, then competition is indicated as the primary source of density dependence.

Overall, the factorial experimental design is especially valuable in studies of open populations, including plants with wind-dispersed seeds, insects with dispersive life history stages, and many marine organisms with dispersive larvae and other propagules (Caley et al. 1996). In such populations, recruitment of juveniles from outside the local population may be independent of local reproductive output, so mortality may be the most important source of local density dependence (Hixon et al. 2002). Regarding the focus of this paperdemersal marine fishes-there is increasing evidence that local density dependence manifests as mortality of new recruits (reviews by Myers and Cadigan 1993, Bailey 1994, Hixon and Webster 2002, Osenberg et al. 2002). Although there have been numerous single-factor studies investigating competition and predation separately, the relative roles of these interactions in causing density-dependent mortality in marine fishes have been explored only recently.

\section{Density-dependent mortality in demersal marine fishes}

The above experimental design and its variants have been previously applied to new recruits of about a dozen species of marine fish, all small demersal species (Table 1). Although all studies occurred in shallow subtidal habitats (temperate kelp forests, tropical coral reefs), a reasonable breadth of families (Scorpaenidae, Embiotocidae, Pomacentridae, Labridae, Gobiidae) and geographic regions (Australia, Bahamas, California, French Polynesia) are represented.

Overall, experimental studies of 12 of 14 species demonstrated that predation was an important source of density-dependent mortality (Table 1, Cases 3 or 4). The two exceptions indicated density-independent mortality (Case 1) in experiments lasting from 30 to 140 days (Forrester and Steele 2000, Webster 2002). Except for the results reported here, no previous studies have found that competition is important in the absence of predators (Fig. 1, Cases 2 or 5), or that competition is of overriding importance, regardless of the presence or absence of predators (Case 6). Prior field experiments ranged from two hours to 140 days in duration, suggesting the possibility that some were so short that they underestimated the importance of competition for food and other nonrefuge resources.

Here, we report a factorial manipulation of conspecific recruit density and resident predators over a period long enough to estimate their relative and interactive effects on survival to adulthood. We synthesize our results with prior studies to provide a conceptual framework regarding the processes causing density-dependent mortality in demersal marine fishes and perhaps other species with similar life histories.

\section{Methods \\ Study system}

The study species is one of the most common damselfishes (Family Pomacentridae) on shallow parts of the Great Barrier Reef, the Ambon damselfish (Pomacentrus amboinensis). Growing to a total length of $\sim 11 \mathrm{~cm}$ (8 cm standard length), this species feeds in loose aggregations near patches of spatially complex corals, taking refuge in these corals when approached by predators and at night (Allen 1991). At the study site in the lagoon of Lizard Island on the northern Great Barrier Reef $\left(14^{\circ} 40^{\prime} \mathrm{S}, 145^{\circ} 28^{\prime} \mathrm{E}\right.$; see Appendix A), $P$. amboinensis is particularly abundant on patches of the dominant, highly complex, branching coral, Porites cylindrica, which provides ample refuge space relative to other corals (Fig. 7). The sand-bottom lagoon at this site, 8-12 m deep, is lined mostly by this coral, large thickets of which occasionally break off during major storms and roll to the lagoon floor, forming distinct patch reefs that support tens of reef-fish species and hundreds of individuals (Webster 2002, Webster and Almany 2002). Although P. amboinensis is reported to consume both benthic algae and zooplankton (Allen 1991), the reefs we studied comprised live coral and supported virtually no algae. Thus, we observed this species feeding only on passing plankton.

\section{Experimental design}

We tested the predictions in Fig. 1 by examining survivorship of new recruits of $P$. amboinensis sub- 
TABLE 1. Previous field experiments that have examined the relative roles of predation and competition in testing for density-dependent mortality of demersal marine fishes.

\begin{tabular}{|c|c|c|c|c|}
\hline $\begin{array}{c}\text { Species } \\
\text { (common name) }\end{array}$ & $\begin{array}{l}\text { Location and } \\
\text { habitat }\end{array}$ & $\begin{array}{l}\text { Duration } \\
\text { (d or } \mathrm{h})\end{array}$ & $\begin{array}{l}\text { Results } \\
\text { (see Fig. 1) }\end{array}$ & Source \\
\hline $\begin{array}{l}\text { Chromis cyanea } \\
\text { (blue chromis) }\end{array}$ & $\begin{array}{l}\text { Bahamas } \\
\text { coral reef }\end{array}$ & $30 \mathrm{~d}$ & Case 4 & Hixon and Carr (1997) \\
\hline $\begin{array}{l}\text { Acanthochromis polyacanthus } \\
\text { (spiny chromis) }\end{array}$ & $\begin{array}{l}\text { Australia } \\
\text { coral reef }\end{array}$ & $<2 \mathrm{~d}$ & Case 4 & Connell (1998) \\
\hline $\begin{array}{l}\text { Coryphopterus dalli } \\
\text { (blue-banded goby) }\end{array}$ & $\begin{array}{l}\text { California } \\
\text { kelp forest }\end{array}$ & $21 \mathrm{~d}$ & Case 3 or 4 & $\begin{array}{l}\text { Forrester and Steele } \\
\quad(2000)\end{array}$ \\
\hline $\begin{array}{l}\text { Coryphopterus glaucofraenum } \\
\text { (bridled goby) }\end{array}$ & $\begin{array}{l}\text { Bahamas } \\
\text { coral reef }\end{array}$ & $30-55 \mathrm{~d}$ & Case 4 & $\begin{array}{l}\text { Forrester and Steele } \\
(2000)\end{array}$ \\
\hline $\begin{array}{l}\text { Coryphopterus nicholsii } \\
\text { (black-eye goby) }\end{array}$ & $\begin{array}{l}\text { California } \\
\text { kelp forest }\end{array}$ & $30-140 \mathrm{~d}$ & Case 1 & $\begin{array}{l}\text { Forrester and Steele } \\
(2000)\end{array}$ \\
\hline $\begin{array}{l}\text { Brachyistius frenatus } \\
\quad \text { (kelp perch) }\end{array}$ & $\begin{array}{l}\text { California } \\
\text { kelp forest }\end{array}$ & $2 \mathrm{~h}$ & Case 4 & Anderson (2001) \\
\hline $\begin{array}{l}\text { Stegastes partitus } \\
\quad \text { (bicolor damselfish) }\end{array}$ & $\begin{array}{l}\text { Bahamas } \\
\text { coral reef }\end{array}$ & $54 \mathrm{~d}$ & Case 3 & Carr et al. (2002) \\
\hline $\begin{array}{l}\text { Dascyllus flavicaudus } \\
\quad \text { (yellow-tailed dascyllus) }\end{array}$ & $\begin{array}{l}\text { French Polynesia } \\
\text { coral reef }\end{array}$ & $3 \mathrm{~d}$ & Case 3 & $\begin{array}{l}\text { Holbrook and Schmitt } \\
\text { (2002) }\end{array}$ \\
\hline $\begin{array}{l}\text { Dascyllus trimaculatus } \\
\quad \text { (three-spot dascyllus) }\end{array}$ & $\begin{array}{l}\text { French Polynesia } \\
\text { coral reef }\end{array}$ & $3-10 d$ & Case 3 & $\begin{array}{l}\text { Holbrook and Schmitt } \\
\text { (2002) }\end{array}$ \\
\hline $\begin{array}{l}\text { Thalassoma hardwicke } \\
\text { (six-bar wrasse) }\end{array}$ & $\begin{array}{l}\text { French Polynesia } \\
\text { coral reef }\end{array}$ & $7 \mathrm{~d}$ & Case 3 or 4 & Shima (2002) \\
\hline $\begin{array}{l}\text { Pomacentrus amboinensis } \\
\text { (Ambon damselfish) }\end{array}$ & $\begin{array}{l}\text { Australia } \\
\text { coral reef }\end{array}$ & $50 \mathrm{~d}$ & Case 3 or 4 & Webster (2002) \\
\hline $\begin{array}{l}\text { Neopomacentrus cyanomos } \\
\quad \text { (regal demoiselle) }\end{array}$ & $\begin{array}{l}\text { Australia } \\
\text { coral reef }\end{array}$ & $50 \mathrm{~d}$ & Case 1 & Webster (2002) \\
\hline $\begin{array}{l}\text { Gramma loreto } \\
\quad \text { (fairy basslet) }\end{array}$ & $\begin{array}{l}\text { Bahamas } \\
\text { coral reef }\end{array}$ & $50 \mathrm{~d}$ & Case 4 & Webster (2003) \\
\hline $\begin{array}{l}\text { Sebastes atrovirens } \\
\quad \text { (kelp rockfish) }\end{array}$ & $\begin{array}{l}\text { California } \\
\text { kelp forest }\end{array}$ & $27 \mathrm{~d}$ & Case 3 or 4 & Johnson (in press) \\
\hline
\end{tabular}

Notes: Results are presented in chronological order of publication date as cases presented in Fig. 1. Note that all previous studies have demonstrated Cases 1,3, and 4, and that some results were somewhat equivocal because supplemental data were unavailable to distinguish between Cases 3 and 4.

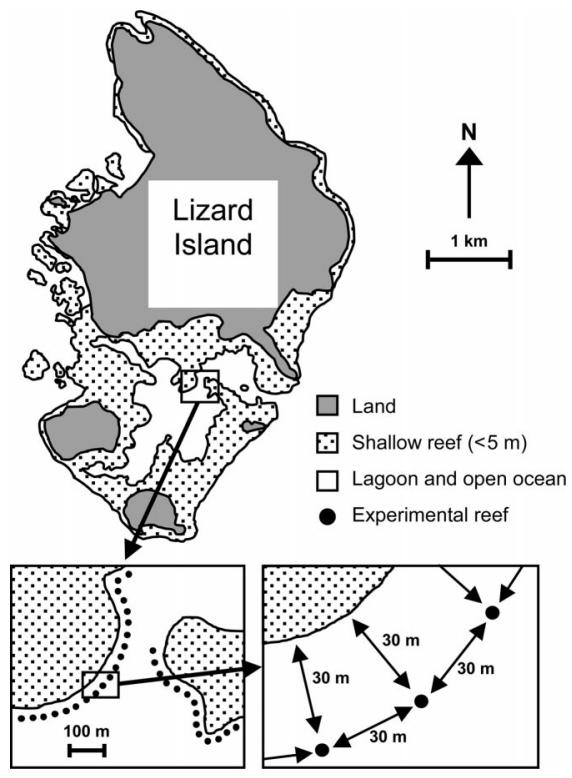

FIG. 2. Map of Lizard Island showing the location and layout of 48 comparably sized patch reefs of Porites cylindrica used in the experiment. Individual reefs not illustrated extended clockwise along the perimeter of the lagoon, as shown. jected to cross-factored densities $(5,15$, and 25 recruits per reef) and risk of predation (resident predators present vs. absent) on comparable sets of patch reefs. In October 1993, divers manipulated 48 patch reefs of $P$. cylindrica coral in the lagoon of Lizard Island, standardizing their size $(3 \mathrm{~m}$ long $\times 1 \mathrm{~m}$ wide $\times 0.75 \mathrm{~m}$ tall) and isolation (30 m from each other as well as from other reefs; Fig. 2). Tagging studies demonstrated that between-reef movement of $P$. amboinensis was negligible at these distances (G. P. Jones, unpublished data). The resident fish communities appeared unaffected by habitat standardization, yet, nonetheless, the start of the experiment was delayed for three months to provide an adjustment period. As reefs were located linearly along the edge of large contiguous lagoonal reefs (Fig. 2), a randomized block design incorporating eight reefs in each of the six treatments was used to minimize any confounding effects of natural gradients across the lagoon. The experiment began in January 1994 at the end of the recruitment season, after which there was no subsequent larval settlement for that season. This timing ensured that experimental cohorts were not confounded by subsequent recruitment during the same year. In establishing reef treatments, we first manipulated predators, then adjusted recruit densities.

Resident predators were removed from "predatorabsent" reefs by divers using hand nets and the fish 
anesthetic quinaldine. To determine the appropriate "predator-present" treatment, we determined from preliminary censuses that the two most common of six species of site-attached predators resident on these patch reefs, accounting for $84 \%$ of all individuals, were the grouper Cephalopholis boenak $(0.97 \pm 0.13 C$. boenak per reef [mean $\pm \mathrm{SE}]$ ) and grouper-like Pseudochromis fuscus $(0.60 \pm 0.12 P$. fuscus per reef $)$. These small piscivores grow to $24 \mathrm{~cm}$ and $9 \mathrm{~cm}$ total length, respectively (Randall et al. 1990), and can swim between the branches of Porites cylindrica only with some difficulty. The total density of all resident piscivores combined was $1.87 \pm 0.15$ predators per reef. Therefore, to emulate average natural densities, the resident predator community on each predator-present reef was adjusted to one adult individual each of $C$. boenak and $P$. fuscus by removal from predator-absent reefs and/or adding to predator-present reefs. Note that schools of jacks (Carangoides ferdau) occasionally visited these reefs, so potential transient predators were not manipulated.

A visual census of all 48 experimental reefs before any manipulations revealed that the mean number of recruits of $P$. amboinensis was 16 per reef $(n=506$, $\mathrm{SD}=1.9)$. We therefore selected our experimental densities to be 5,15 , and 25 new recruits per reef, which included the range of densities experienced by $89 \%$ of naturally recruited fish. All recent recruits were collected by hand net and anesthetic, and from this pooled population, settlers were transplanted onto the reefs at appropriate densities. A subsample of 61 transplanted recruits measured $14.0 \pm 0.2 \mathrm{~mm}$ standard length (mean $\pm \mathrm{SE}$ ). All larger P. amboinensis and other damselfishes were removed from the reefs at the beginning of the experiment.

Following these manipulations, reefs were censused by divers daily for 10 days to determine whether there were any immediate effects of the transplantation process on prey numbers, as well as to assess whether emigration rendered the treatments ineffective. There were no substantial changes in the abundance of either predators or prey during this initial period. Subsequently, the reefs were visually censused five times for both predators and $P$. amboinensis numbers and sizes (within 5-mm size classes) approximately bimonthly for 10 months. During this latter period, predator treatments remained intact, and strong site fidelity by these predators at this site was later confirmed by tagging studies (Stewart and Jones 2001). It was also easy to distinguish by size damselfish in the experimental cohorts from new recruits that appeared toward the end of the 10 months, which was the beginning of the following year's recruitment season. A final census was conducted 17 months after the beginning of the experiment, by which time the surviving $P$. amboinensis were sexually mature. At that time, all $P$. amboinensis were collected from the reefs to confirm identification of the experimental cohort via otolith (ear stone) aging and length-age relationships.

\section{Statistical analysis}

Results from the experiment, expressed as per capita (proportional) mortality of prey per reef at each census, were examined by complete randomized-block, twoway ANOVA, with predator treatment and recruit density as fixed factors (SigmaStat, Version 3.0, Systat Software, Point Richmond, California, USA). ANOVA was followed by Bonferroni paired comparisons. Before analysis, normality was tested by KolmogorovSmirnov tests, homogeneity of variances by Levene Median tests, and transforms were used as needed. Relative effect sizes were calculated as recommended by Graham and Edwards (2001) and detailed by Winer (1971:428-430).

To examine temporal trends in the body-size structure of experimental cohorts, each fish was assigned to the midpoint of its 5-mm size class. If competition for food affects size structure, then one would expect variance in body length within a cohort of new recruits to increase as dominant individuals grow more rapidly than inferior competitors. However, differential growth could also be due to initial physiological condition or even genetic variation (McCormick 1998). If stunted inferior competitors eventually suffer high mortality, then one would expect variance in the size structure to subsequently decrease, although this latter pattern could be confounded by fish approaching asymptotic sizes. Thus, temporal trends in the size structure of cohorts can provide evidence consistent with competition for food, but certainly do not provide a definitive test.

Given that mortality occurred through time, and thus sample sizes (number of fish per cohort) decreased, two appropriate measures of variance in body size within a particular reef at a particular time are: (1) the coefficient of variation $(\mathrm{CV})$, which is the standard deviation expressed as a proportion of the mean, and (2) the Gini coefficient $(G)$, which is a measure of the inequality in a size distribution, literally the mean of the difference between every possible pair of individuals divided by the mean size, which ranges from 0 to 1 (Damgaard and Weiner 2000). We therefore compared the CV and $G$ of standard body lengths within reefs of a particular density treatment ( $n=8$ per treatment) by complete randomized-block, two-way ANOVA, with predator treatment and sampling date as fixed factors, followed by Bonferroni paired comparisons (and preceded by tests of assumptions and any necessary data transformations). If competition for food was occurring as reasoned in the previous paragraph, then the $\mathrm{CV}$ and $G$ of body size midway through the experiment should be significantly greater than either at the beginning or at the end of the experiment within any given density treatment. 


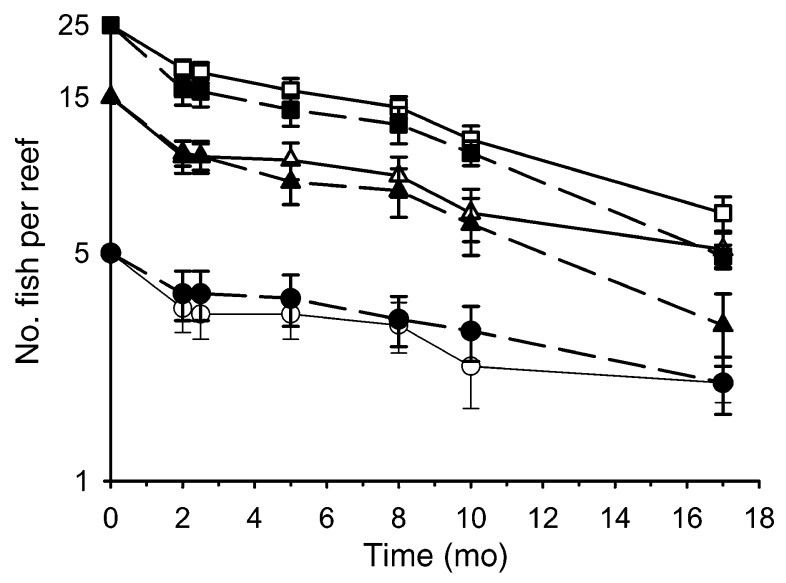

FIG. 3. Survivorship curves $\left(\log _{10}\right)$ of experimental cohorts of Pomacentrus amboinensis in treatments where resident predators were present (solid symbols) or absent (open symbols). Each curve represents eight cohorts (mean \pm SE) spanning initial densities of 5,15 , or 25 new recruits per reef.

\section{RESUlts}

Mortality

Survivorship curves showed that densities of experimental cohorts of $P$. amboinensis, both with and without resident predators, gradually converged over nearly 1.5 years (Fig. 3). Among the six experimental treatments (three initial densities of 5, 15, or 25 fish per reef $\times 2$ predator presence-absence categories), final mean $( \pm \mathrm{SE})$ densities ranged only from $2.00( \pm 0.40)$ to $6.63( \pm 0.80)$ fish per reef, displaying substantial convergence (Fig. 4A). By the end of the experiment, all remaining fish over $44 \mathrm{~mm}$ standard length $(>95 \%$ of all individuals) were sexually mature and there was a grand average of four adults per reef.

The final pattern of per capita mortality clearly matched Case 6 in Fig. 1. Mortality rates were initially examined from the start of the experiment to each subsequent census, since the focus was survival over the complete life-span of each cohort. Over the first 10 months of the experiment, mortality was density independent and not significantly different between predator-present and predator-absent reefs (for ANOVAs see Appendix B). However, by the end of the experiment, 17 months after the start, mortality was highly density dependent, even though there was still no significant effect of resident predators (Fig. 4B). Multiple comparisons revealed that 17 -mo per capita mortality in the low-density treatment was significantly less than in the medium- and high-density treatments, which were not significantly different from each other. Effect sizes hovered near zero until the final census, which suggested that the effect of density per se (i.e., competition) increased dramatically over this period relative to the effect of predation (Fig. 5).

The appearance of density dependence only during the last seven months of the experiment led us to ex- amine the course of mortality from 10 months (no significant pattern) to 17 months (significant density dependence). This ANOVA revealed that both predation and density had significant effects as the fish approached sexual maturity, evidenced by the effect sizes of both factors being substantial (Fig. 5). Comparing the results between zero and 17 months, with those between 10 and 17 months, we conclude that competition was the source of density dependence, with predation serving only as the proximate agent of death. In all ANOVAs, there was no significant interaction between the predation and competition treatments, indicating that the effect of competition was not modified by the presence of predators or vice versa.

\section{Size structure}

Variation in the size structure of $P$. amboinensis per reef, measured by both the $\mathrm{CV}$ and $G$ of cohort body lengths, changed over the course of the experiment. Both measures tended to increase during the first half, then decline during the second half, especially in the high-density treatments (Fig. 6; see also Appendix C,
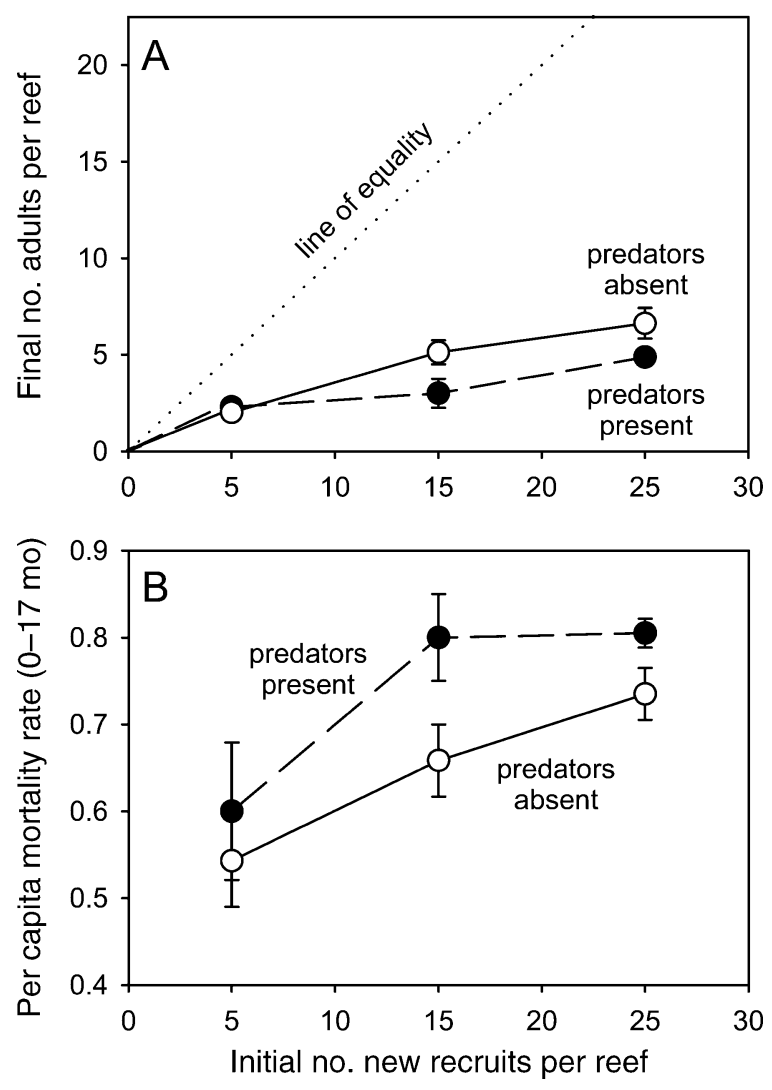

FIG. 4. Patterns of (A) recruit-adult relationships and (B) per capita mortality (cf. Fig. 1) of experimental cohorts of Pomacentrus amboinensis in the presence and absence of resident predators. Each symbol represents eight cohorts (mean $\pm \mathrm{SE}$ ) spanning initial densities of 5,15 , or 25 new recruits per reef. See Appendix B for analyses of per capita mortality rates. 


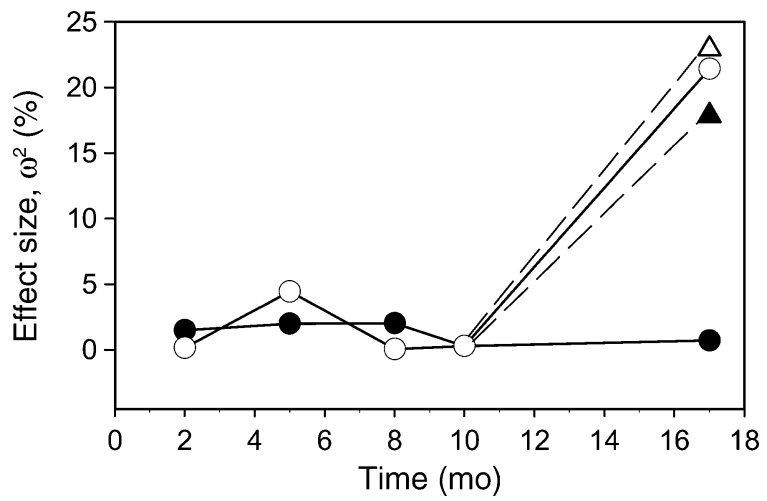

FIG. 5. Effect sizes $\left(\omega^{2}\right)$ of density (open symbols) and predation (solid symbols) at different time intervals during the experiment. Circles are effect sizes from the start of the experiment until the indicated time post-settlement. Triangles are effect sizes from month 10 to the end of the experiment at month 17. Note that substantial effects are evident only toward the end of the experiment.

Fig. 1C). The overall temporal pattern was nonsignificant in the low-density treatment, significant in the medium-density treatment only for the $\mathrm{CV}$ measure, and highly significant for both the $\mathrm{CV}$ and $G$ measures in the high-density treatment (for all ANOVAs see Appendix C). As with mortality rates, there was no significant effect of resident predators. Multiple comparisons revealed that significant changes in the $\mathrm{CV}$ measure occurred between the middle and end of the experiment in the medium-density treatments. In the high-density treatments, this change was significant between the beginning and middle of the experiment, as well as between the middle and end for both the $\mathrm{CV}$ and $G$ measures. By the end of the experiment, remaining fish on all reefs combined averaged $51.8 \pm$ $5.1 \mathrm{~mm}$ standard length (mean $\pm \mathrm{SD}, n=189$ ), well less than the asymptotic size of about $80 \mathrm{~mm}$ standard length (Allen 1991).

\section{DISCUSSION}

Processes causing density-dependent mortality

Density-dependent mortality in temperate and tropical demersal marine fishes, including both commercial fisheries species and unexploited species, is now well documented (reviews by Myers and Cadigan 1993, Hixon and Webster 2002, Myers 2002, Osenberg et al. 2002). However, the processes underlying this important source of population regulation are relatively little known. Density-dependent mortality of $P$. amboinensis was not detected during the first 10 months of our 17mo experiment. During this initial period, far longer than previous experiments reviewed in Table 1, per capita mortality of new recruits was density independent, and there was no obvious effect of site-attached resident predators on survival of this planktivorous damselfish. Density-dependent mortality appeared in strength only during the last seven months of the ex- periment. The strength of density dependence was apparently neither determined by nor moderated by the presence of predators.

At face value, the short-term result was surprising because piscivores typically have rapid and substantial effects on populations and communities of coral-reef fishes (reviews by Hixon 1991, Hixon and Beets 1993, Hixon and Webster 2002). Why were resident predators ineffective in this system? First, the natural mean density of resident predators per reef at the time of our experiments was about half that observed in another experiment on the same reefs, although densities of $P$. amboinensis were comparable (Webster 2002). In that experiment, conducted in 1999, mortality of $P$. amboinensis recruits in the presence of predators was weakly density dependent within only 50 days. Second, the highly complex, branching coral comprising these reefs provided ample spatial refuges for small fish compared to experiments conducted on reefs dominated by massive corals (Fig. 7). Indeed, Beukers and Jones (1998) demonstrated experimentally for the ecologi-
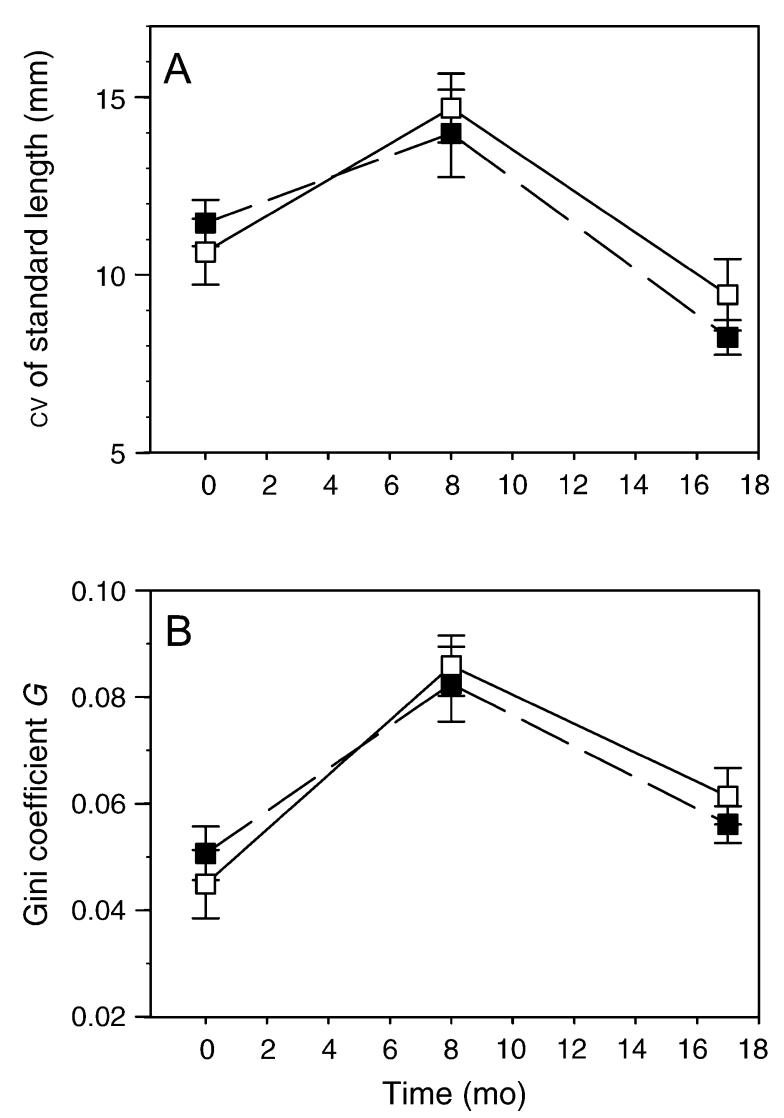

FIG. 6. Change in (A) the coefficient of variation (CV) and (B) Gini coefficient $(G)$ of body lengths within experimental cohorts of Pomacentrus amboinensis in high-density treatments where resident predators were present (solid symbols) or absent (open symbols). Each curve represents eight cohorts (mean $\pm \mathrm{SE}$ ) of 25 new recruits per reef. See Appendix C, Fig. C1 for graphs of other density treatments and analyses. 

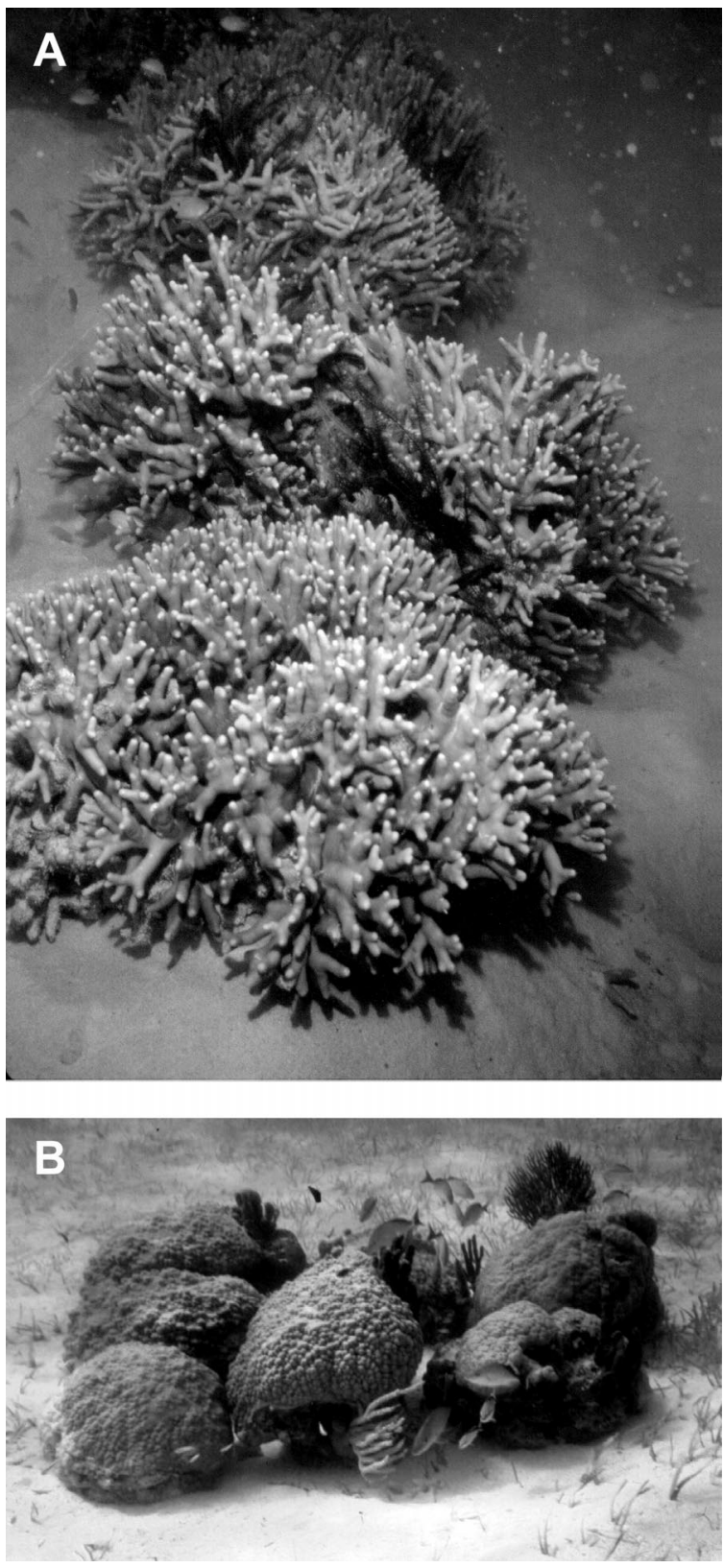

FIg. 7. (A) Patch reef of Porites cylindrica coral in the Lizard Island lagoon, used in the present experiment. (B) Patch reef of mostly Porites astereoides coral in the Bahamas, used in similar experiments (Hixon and Carr 1997, Carr et al. 2002). Note the relative availability of shelter for small fishes. In both photos, the coral heads are $\sim 50-100 \mathrm{~cm}$ in diameter. Photos were taken by M. A. Hixon.

cally similar P. moluccensis at Lizard Island that increasing habitat complexity substantially reduced predation rates by resident piscivores (the same predator species that we studied). On reefs dominated by massive corals of relatively simple structure, piscivores rapidly induce strong density-dependent mortality on ecologically similar species of damselfish (Hixon and Carr 1997, Carr et al. 2002). Both Hixon and Carr
(1997) and Forrester and Steele (2004) demonstrated experimentally that density-dependent mortality can disappear when prey refuges are abundant.

Regardless of the cause, the absence of effective predation explains why mortality was density independent during the first 10 months of the experiment. The other potential source of density-dependent mortality-competition-may take substantial time to manifest. Changes in body-size frequency distributions were consistent with exploitative competition for food, perhaps augmented by interference competition as the fish became sexually mature and social hierarchies developed (Jones 1987). Variance in the sizes of juveniles initially increased, significantly at high densities, indicating differential growth from an initial narrow range of recruit lengths to greater variation midway during the experiment. This pattern suggests either innate differences in growth rates among juveniles, or more likely, exploitative competition for planktonic food that did not initially manifest as increased mortality. Socially dominant juveniles grow faster than subordinates, as previously demonstrated for P. amboinensis (Jones 1987) and other planktivorous damselfishes (Stevenson 1972, Forrester 1991, Buston 2003). Fishes are well documented to remove nearly all the zooplankton flowing over coral reefs (Hamner et al. 1988, Hobson 1991, Motro et al. 2005), and reef fish undergo substantial increases in growth, earlier maturation, and increased fecundity in populations given supplemental food (Jones 1986, Forrester 1990, Jones and McCormick 2002).

By whatever specific mechanism, competition during the first half of the experiment (0-10 mo) was apparently strong enough to influence growth, but not survival, as documented previously for a variety of reef fishes, including other damselfishes (reviews by Jones 1991, Jones and McCormick 2002). Thus, had the experiment ended after 10 months, one could have concluded that $P$. amboinensis at Lizard Island undergoes density-independent mortality and therefore is recruitment limited (sensu, Doherty and Fowler 1994, Doherty 1998). This result advises caution regarding the interpretation of short-term experimental tests for density dependence (see Harrison and Cappuccino 1995).

During the last part of the experiment (10-17 mo), strong density-dependent mortality emerged, and variance in fish sizes declined, especially in high-density treatments, so that each reef ultimately supported about four mature adults from the original cohort. These results indicate that exploitative and perhaps interference competition eventually became sufficiently severe that slow-growing fish, more vulnerable to predation, were removed by resident and/or transient predators (see also Forrester 1990). This interpretation is consistent with what has been called the "growth-mortality hypothesis" or "stage-duration hypothesis," which predicts that increasing competition for food will increase the time required for small fish to grow to a size relatively

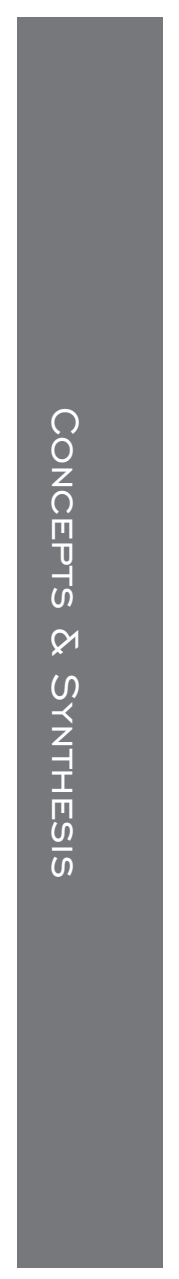




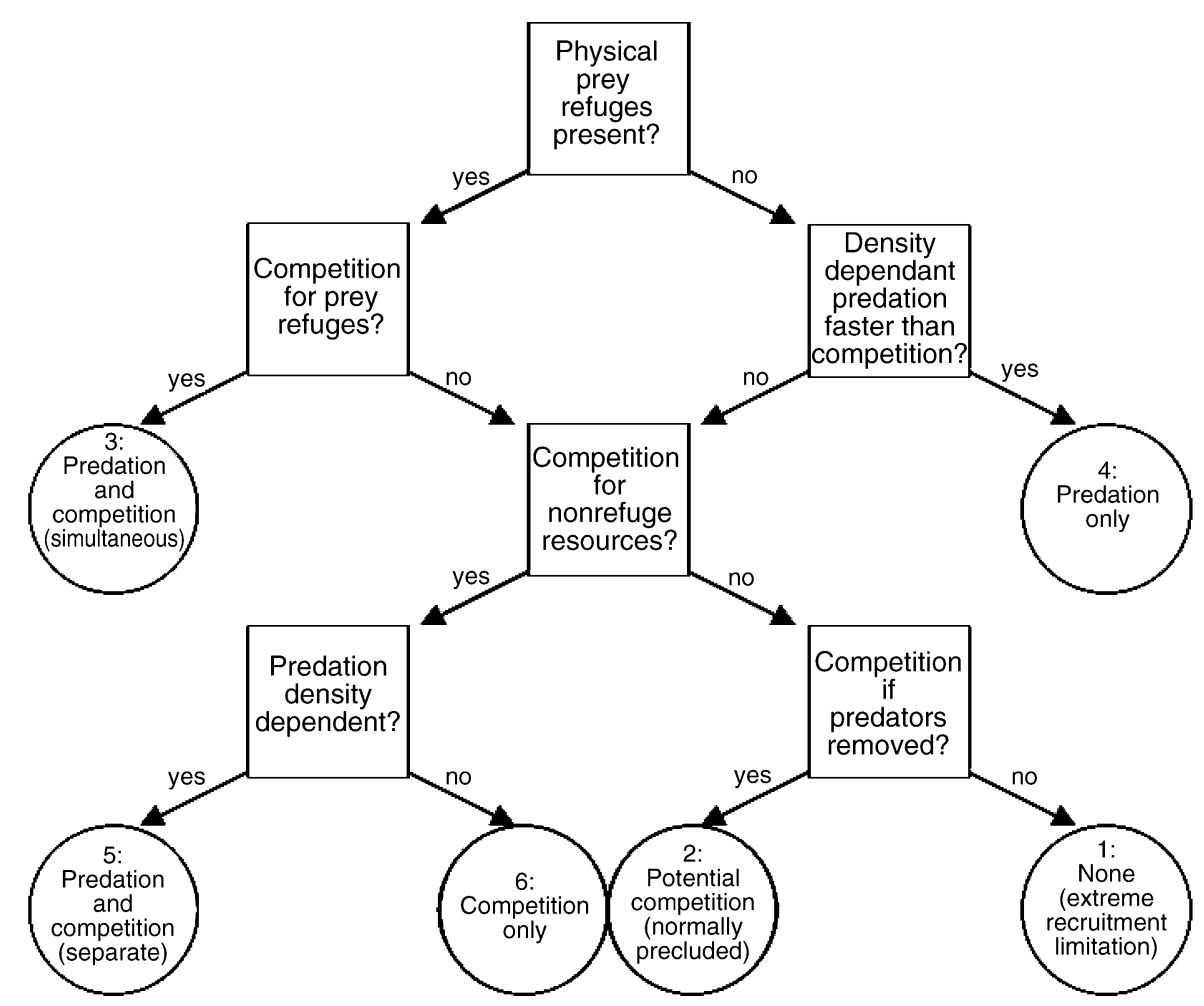

FIG. 8. Synthetic flowchart explaining how the interplay of competition, predation, and prey refuges determines the source of density-dependent mortality in demersal marine fishes. Numbered cases in circles refer to Fig. 1.

invulnerable to predation, thereby increasing overall mortality (reviews by Houde 1987, Sogard 1997). Additionally, it is conceivable (although we believe unlikely) that competition for prey refuges eventually became important as fish outgrew smaller holes in the reefs, thus becoming more vulnerable to predation. In any case, because the fish had not approached their asymptotic body size by the end of the experiment, it appears that the decline in size variation within cohorts was due to differential mortality. Overall, predation was apparently the proximate cause of death during our experiment, with competition being the ultimate cause of long-term density-dependent mortality.

\section{Synthesis}

Combined with similar previous experiments (Table 1), our results help to provide a conceptual framework regarding the interplay of competition, predation, and prey refuges in causing density-dependent post-settlement mortality in demersal marine fishes and similar species. Fig. 8 illustrates the circumstances leading to the alternative experimental outcomes described in Fig. 1. Assuming the experiment runs long enough to demonstrate the absence of density-dependent post-settlement mortality, the density independent null outcome (Case 1) suggests extreme recruitment limitation. In such cases, population regulation must occur elsewhere in the local population or metapopulation via density- dependent fecundity or perhaps presettlement density dependence during the larval stage (Hixon and Webster 2002, Hixon et al. 2002, Sandin and Pacala 2005a). Available evidence suggests that the latter is rare in marine fish larvae (Houde 1987, Bailey and Houde 1989, Heath 1992). Recruitment limitation may be due to low larval supply (Doherty and Fowler 1994, Doherty 1998, 2002) and/or high density-independent post-settlement mortality due to predation, physical disturbance, or other abiotic factors (Caley 1998, Levin 1998).

\section{Ramifications for marine fisheries}

Including our study, four of the six cases illustrated in Figs. 1 and 8 have now been demonstrated for demersal marine fishes (Table 1). This growing body of evidence indicates that predation on new recruits, whether or not competition is also involved, is the primary source of density-dependent mortality in most species. This conclusion corroborates earlier hypotheses that a source of density-dependent mortality in exploited marine populations is predation on juveniles (Sissenwine 1984, Rothschild 1986, Houde 1987, Myers and Cadigan 1993, Bailey 1994). If generally applicable, this finding contradicts a foundational assumption of conventional single-species fisheries biology: that intraspecific competition alone is the source of demographic density dependence (historical review 
by Smith 1994). The results of the present experiment suggest that this assumption may be true for demersal species only when prey refuges are not limiting or predators are rare.

If predation is a major source of population regulation in marine fishes, then overfishing of predatory species, as appears to be rampant worldwide (e.g., Myers and Worm 2003, Ward and Myers 2005), could result in destabilization of population dynamics of prey species by removing an important source of density dependence (see also Pimm and Hyman 1987).

All told, the source of density-dependent mortality in marine fishes, and probably other species with similar life histories, is seldom a simple either/or dichotomy between competition and predation, but rather a rich system-specific interplay of these interactions in the context of variable recruitment, habitat structure, and abiotic conditions. The consequences of neither incorporating interactions among multiple species into fisheries models, nor otherwise implementing ecosystem-based management (Pikitch et al. 2004), are reflected in the global crisis in marine fisheries.

\section{ACKNOWLEDGMENTS}

We thank J. Beukers-Stewart, B. Beukers-Stewart, and C. Syms for field assistance, the Lizard Island Research Station for hosting our study, and M. Webster for Fig. 2. The manuscript benefited from constructive comments by D. Johnson, C. Stallings, and two anonymous reviewers. MAH was supported by NSF Grant OCE-92-17163 and a Fulbright Senior Scholar Award during field work, and by NSF Grant OCE00-93976 during preparation of the manuscript. GPJ acknowledges support from the Australian Research Council Large Grants Scheme. Authorship is equal.

\section{Literature Cited}

Abrams, P. A., and L. R. Ginzburg. 2000. The nature of predation: prey dependent, ratio dependent or neither? Trends in Ecology and Evolution 15:337-341.

Allen, G. R. 1991. Damselfishes of the world. Mergus Publishers, Melle, Germany.

Anderson, T. W. 2001. Predator responses, prey refuges, and density-dependent mortality of a marine fish. Ecology 82: 245-257.

Armsworth, P. R. 2002. Recruitment limitation, population regulation, and larval connectivity in reef fish metapopulations. Ecology 83:1092-1104.

Bailey, K. M. 1994. Predation on juvenile flatfish and recruitment variability. Netherlands Journal of Sea Research 32:175-189.

Bailey, K. M., and E. D. Houde. 1989. Predation on eggs and larvae of marine fishes and the recruitment problem. Advances in Marine Biology 25:1-83.

Beukers, J. S., and G. P. Jones. 1998. Habitat complexity modifies the impact of piscivores on a coral reef fish population. Oecologia 114:50-59.

Booth, D. J. 1995. Juvenile groups in a coral-reef damselfish: density-dependent effects on individual fitness and demography. Ecology 76:91-106.

Buston, P. 2003. Size and growth modification in clownfish. Nature 424:145-146.

Caley, M. J. 1998. Age-specific mortality rates in reef fishes: evidence and implications. Australian Journal of Ecology 23:241-245.

Caley, M. J., M. H. Carr, M. A. Hixon, T. P. Hughes, G. P. Jones, and B. A. Menge. 1996. Recruitment and the local dynamics of open marine populations. Annual Review of Ecology and Systematics 27:477-500.

Carr, M. H., T. W. Anderson, and M. A. Hixon. 2002. Biodiversity, population regulation, and the stability of coralreef fish communities. Proceedings of the National Academy of Sciences 99:11241-11245.

Chase, J. M., P. A. Abrams, J. P. Grover, S. Diehl, P. Chesson, R. D. Holt, S. A. Richards, R. M. Nisbet, and T. J. Case. 2002. The interaction between predation and competition: a review and synthesis. Ecology Letters 5:302-315.

Chesson, P. L. 1998. Recruitment limitation: a theoretical perspective. Australian Journal of Ecology 23:234-240.

Connell, J. H. 1975. Some mechanisms producing structure in natural communities: a model and evidence from field experiments. Pages 460-490 in M. L. Cody and J. A. Diamond, editors. Ecology and evolution of communities. Belknap-Harvard University Press, Cambridge, Massachusetts, USA.

Connell, S. D. 1998. Effects of predators on growth, mortality and abundance of a juvenile reef-fish: evidence from manipulations of predator and prey abundance. Marine Ecology Progress Series 169:251-261.

Damgaard, C., and J. Weiner. 2000. Describing inequality in plant size or fecundity. Ecology 81:1139-1142.

Doherty, P. J. 1998. Recruitment limitation: definitions, predictions and tests. Pages 129-131 in G. P. Jones, P. J. Doherty, B. D. Mapstone, and L. Howlett, editors. Reef fish '95: recruitment and population dynamics of coral reef fishes. CRC Reef Research Center, Townsville, Australia.

Doherty, P. J. 2002. Variable replenishment and the dynamics of reef fish populations. Pages 327-355 in P. F. Sale, editor. Coral reef fishes: dynamics and diversity in a complex ecosystem. Academic Press, San Diego, California, USA.

Doherty, P., and A. Fowler. 1994. An empirical test of recruitment limitation in a coral reef fish. Science 263:935939.

Forrester, G. E. 1990. Factors influencing the juvenile demography of a coral reef fish. Ecology 71:1666-1681.

Forrester, G. E. 1991. Social rank, individual size and group composition as determinants of food consumption by humbug damselfish, Dascyllus aruanus. Animal Behaviour 42: 701-711.

Forrester, G. E., and M. A. Steele. 2000. Variation in the presence and cause of density-dependent mortality in three species of reef fishes. Ecology 81:2416-2427.

Forrester, G. E., and M. A. Steele. 2004. Predators, prey refuges, and the spatial scaling of density-dependent prey mortality. Ecology 85:1332-1342.

Graham, M. H., and M. S. Edwards. 2001. Statistical significance versus fit: estimating the importance of individual factors in ecological analysis of variance. Oikos 93:505513.

Gurevitch, J., J. A. Morrison, and L. V. Hedges. 2000. The interaction between competition and predation: a metaanalysis of field experiments. American Naturalist 155: 435-453.

Hamner, W. M., M. S. Jones, J. H. Carleton, I. R. Hauri, and D. M. Williams. 1988. Zooplankton, planktivorous fish, and water currents on a windward reef face: Great Barrier Reef, Australia. Bulletin of Marine Science 42:459-479.

Harrison, S., and N. Cappuccino. 1995. Using density-manipulation experiments to study population regulation. Pages 131-147 in N. Cappuccino and P. W. Price, editors. Population dynamics: new approaches and synthesis. Academic Press, San Diego, California, USA.

Heath, M. R. 1992. Field investigations of the early life stages of marine fish. Advances in Marine Biology 28:1-174.

Hixon, M. A. 1991. Predation as a process structuring coral reef fish communities. Pages 475-508 in P. F. Sale, editor.

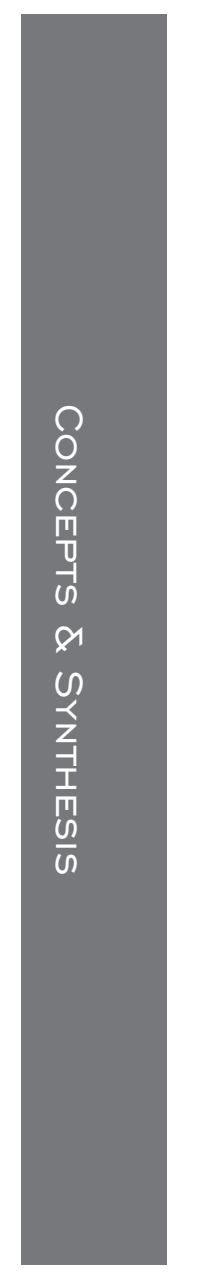


The ecology of fishes on coral reefs. Academic Press, San Diego, California, USA.

Hixon, M. A. 1998. Population dynamics of coral-reef fishes: controversial concepts and hypotheses. Australian Journal of Ecology 23:192-201.

Hixon, M. A., and J. P. Beets. 1993. Predation, prey refuges, and the structure of coral-reef fish assemblages. Ecological Monographs 63:77-101.

Hixon, M. A., and M. H. Carr. 1997. Synergistic predation, density dependence, and population regulation in marine fish. Science 277:946-949.

Hixon, M. A., S. W. Pacala, and S. A. Sandin. 2002. Population regulation: historical context and contemporary challenges of open vs. closed systems. Ecology 83:14901508 .

Hixon, M. A., and M. S. Webster. 2002. Density dependence in reef fish populations. Pages 303-325 in P. F. Sale, editor. Coral reef fishes: dynamics and diversity in a complex ecosystem. Academic Press, San Diego, California, USA.

Hobson, E. S. 1991. Trophic relationships of fishes specialized to feed on zooplankters above coral reefs. Pages 6995 in P. F. Sale, editor. The ecology of fishes on coral reefs. Academic Press, San Diego, California, USA.

Holbrook, S. J., and R. J. Schmitt. 2002. Competition for shelter space causes density-dependent predation mortality in damselfishes. Ecology 83:2855-2868.

Houde, E. D. 1987. Fish early life dynamics and recruitment variability. American Fisheries Society Symposium Series 2:17-29.

Jeffries, M. J., and J. H. Lawton. 1984. Enemy free space and the structure of ecological communities. Biological Journal of the Linnean Society 23:269-286.

Johnson, D. W. In press. Density dependence in marine fish populations revealed by small-scale experiments and largescale observations. Ecology.

Jones, G. P. 1986. Food availability affects growth in a coral reef fish. Oecologia 70:136-139.

Jones, G. P. 1987. Competitive interactions among adults and juveniles in a coral reef fish. Ecology 68:1534-1547.

Jones, G. P. 1991. Postrecruitment processes in the ecology of coral reef fish populations: a multifactorial perspective. Pages 294-328 in P. F. Sale, editor. The ecology of fishes on coral reefs. Academic Press, San Diego, California, USA.

Jones, G. P., and M. I. McCormick. 2002. Interaction between energetic and numerical processes in the ecology of coral reef fish populations. Pages 221-238 in P. F. Sale, editor. Coral reef fishes: dynamics and diversity in a complex ecosystem. Academic Press, San Diego, California, USA.

Levin, P. S. 1998. The significance of variable and densityindependent post-recruitment mortality in local populations of reef fishes. Australian Journal of Ecology 23:246-251.

McCormick, M. I. 1998. Condition and growth of reef fish at settlement: is it important? Australian Journal of Ecology 23:258-264.

Motro, R., I. Ayalon, and A. Genin. 2005. Near-bottom depletion of zooplankton over coral reefs: III: vertical gradient of predation pressure. Coral Reefs 24:95-98.

Murdoch, W. W., and A. Oaten. 1975. Predation and population stability. Advances in Ecological Research 9:1-132.

Myers, R. A. 2002. Recruitment: understanding density-dependence in fish populations. Pages 123-148 in P. J. B. Hart and J. D. Reynolds, editors. Handbook of fish biology and fisheries. 1. Fish biology. Blackwell Science, Malden, Massachusetts, USA.

Myers, R. A., and N. G. Cadigan. 1993. Density-dependent juvenile mortality in marine demersal fish. Canadian Journal of Fisheries and Aquatic Sciences 50:1576-1590.

Myers, R. A., and B. Worm. 2003. Rapid worldwide depletion of predatory fish communities. Nature 423:281-283.
Osenberg, C. W., C. M. S. Mary, R. J. Schmitt, S. J. Holbrook, P. Chesson, and B. Byrne. 2002. Rethinking ecological inference: density dependence in reef fishes. Ecology Letters 5:715-721.

Osenberg, C. W., and G. G. Mittelbach. 1996. The relative importance of resource limitation and predator limitation in food chains. Pages 134-148 in G. A. Polis and K. O. Winemiller, editors. Food webs: interaction of patterns and dynamics. Chapman and Hall, New York, New York, USA.

Pikitch, E. K., et al. 2004. Ecosystem-based fishery management. Science 305:346-347.

Pimm, S. L., and J. B. Hyman. 1987. Ecological stability in the context of multispecies fisheries. Canadian Journal of Fisheries and Aquatic Sciences 44:84-94.

Polis, G. A., C. A. Myers, and R. D. Holt. 1989. The ecology and evolution of intraguild predation: potential competitors that eat each other. Annual Review of Ecology and Systematics 20:297-330.

Randall, J. E., G. R. Allen, and R. C. Steene. 1990. Fishes of the Great Barrier Reef and Coral Sea. University of Hawaii Press, Honolulu, Hawaii, USA.

Rothschild, B. J. 1986. Dynamics of marine fish populations. Harvard University Press, Cambridge, Massachusetts, USA.

Sandin, S. A., and S. W. Pacala. 2005a. Demographic theory of coral reef fish populations with stochastic recruitment: comparing sources of population regulation. American Naturalist 165:107-119.

Sandin, S. A., and S. W. Pacala. 2005b. Fish aggregation results in inversely density-dependent predation on continuous coral reefs. Ecology 86:1520-1530.

Schmitt, R. J., S. J. Holbrook, and C. W. Osenberg. 1999. Quantifying the effects of multiple processes on local abundance: a cohort approach for open populations. Ecology Letters 2:294-303.

Shima, J. S. 2002. Mechanisms of density- and number-dependent population regulation of a coral-reef fish. Marine and Freshwater Research 53:175-179.

Sih, A., P. Crowley, M. McPeek, J. Petranka, and K. Strohmeier. 1985. Predation, competition, and prey communities: a review of field experiments. Annual Review of Ecology and Systematics 16:269-311.

Sih, A., G. Englund, and D. Wooster. 1998. Emergent impacts of multiple predators on prey. Trends in Ecology and Evolution 13:350-355.

Sissenwine, M. P. 1984. Why do fish populations vary? Pages 59-94 in R. M. May, editor. Exploitation of marine communities. Springer-Verlag, Berlin, Germany.

Smith, T. D. 1994. Scaling fisheries: the science of measuring the effects of fishing, 1855-1955. Cambridge University Press, Cambridge, UK.

Sogard, S. M. 1997. Size-selective mortality in the juvenile stage of teleost fish: a review. Bulletin of Marine Science 60:1129-1157.

Stevenson, R. A. 1972. Regulation of feeding behavior of the bicolor damselfish (Eupomacentrus partitus Poey) by environmental factors. Pages 278-302 in H. E. Winn and B. L. Olla, editors. Behavior of marine animals. Volume 2. Vertebrates. Plenum, New York, New York, USA.

Stewart, B. D., and G. P. Jones. 2001. Associations between the abundance of piscivorous fishes and their prey on coral reefs: implications for prey-fish mortality. Marine Biology 138:383-397.

Taylor, R. J. 1984. Predation. Chapman and Hall, London, UK.

Ward, P., and R. A. Myers. 2005. Shifts in open-ocean fish communities coinciding with the commencement of commercial fishing. Ecology 86:835-847.

Webster, M. S. 2002. Role of predators in the early post- 
settlement demography of coral-reef fishes. Oecologia $\mathbf{1 3 1}$ : $52-60$.

Webster, M. S. 2003. Temporal density dependence and population regulation in a marine fish. Ecology 84:623628.
Webster, M. S., and G. R. Almany. 2002. Positive indirect effects in a coral reef fish community. Ecology Letters 5: 549-557.

Winer, B. J. 1971. Statistical principles in experimental design. Second edition. McGraw-Hill, New York, New York, USA.

\section{APPENDIX A}

An aerial photograph of the study site, Lizard Island, Australia, is available in ESA's Electronic Data Archive: Ecological Archives E086-154-A1.

\section{APPENDIX B}

Two-way ANOVAs of per capita mortality rates of cohorts of Pomacentrus amboinensis are available in ESA's Electronic Data Archive: Ecological Archives E086-154-A2.

\section{APPENDIX C}

Two-way ANOVAs of coefficient of variation (CV) and Gini Coefficient $(G)$ of body length of cohorts of Pomacentrus amboinensis and a figure showing change in the $\mathrm{CV}$ and $G$ of body lengths within experimental cohorts of Pomacentrus amboinensis in the presence and absence of resident predators are available in ESA's Electronic Data Archive: Ecological Archives E086-154-A3. 